\title{
Systematic review and meta-analysis of mortality and digoxin use in atrial fibrillation
}

\author{
Waqas Qureshi ${ }^{1}$, Wesley T. O’Neal ${ }^{1}$, Elsayed Z. Soliman ${ }^{1,3}$, Mouaz H. Al-Mallah ${ }^{4,5}$ \\ ${ }^{1}$ Department of Internal Medicine, Division of Cardiovascular Medicine, Wake Forest \\ School of Medicine, Winston-Salem, North Carolina, United States \\ ${ }^{2}$ Epidemiological Cardiology Research Center (EPICARE), Department of Epidemiology and Prevention, \\ Wake Forest School of Medicine, Winston-Salem, North Carolina, United States \\ ${ }^{3}$ Wayne State University School of Medicine, Detroit, Michigan, United Sates \\ ${ }^{4}$ King Abdul Aziz Cardiac Center, King Abdulaziz Medical City, Ministry of National \\ Guard-Health Affairs, Riyadh, Kingdom of Saudi Arabia \\ ${ }^{5}$ King Saud bin Abdulaziz University for Health Sciences, Riyadh, Kingdom of Saudi Arabia
}

\begin{abstract}
Background: There is growing controversy regarding the association between digoxin and mortality in atrial fibrillation $(A F)$. The aim of this analysis was to systematically review digoxin use and risk of mortality in patients with $A F$.

Methods: MEDLINE, EMBASE, GoogleScholar, CINAHL, meeting abstracts, presentations, and Cochrane central databases were searched from inception through December 2014, without language restrictions. For a study to be selected, it had to report the risk of mortality associated with digoxin use in $A F$ patients as an outcome measure. Data were extracted by 2 independent authors. Evidence tables were created.
\end{abstract}

Results: A total of 16 studies ( 6 post hoc analyses of randomized controlled trials) with 111,978 digoxin users and 389,643 non-digoxin users were included. In a random effects model, patients treated with digoxin had a $27 \%$ increased risk of all-cause mortality (pooled HR 1.27; 95\% CI 1.19-1.36) and 21\% increased risk of cardiovascular mortality (pooled HR 1.21; 95\% CI 1.12-1.30) compared with those who did not use digoxin. In a random effects model, the association of digoxin with all-cause mortality was stronger for AF patients without heart failure (pooled HR 1.47; 95\% CI 1.25-1.73) than AF patients with heart failure (pooled HR 1.21; 95\% CI 1.07-1.36, interaction $p=0.06$ ).

Conclusions: Digoxin use in $A F$ is associated with increased risk of all-cause and cardiovascular mortalities. The effect size was larger for AF patients without heart failure than AF patients with heart failure. The study suggests further directed analyses to study the effect that is suggested by this meta-analysis, especially in AF without heart failure. (Cardiol J 2016; 23, 3: 333-343)

Key words: digoxin, mortality, meta-analysis, systematic review, atrial fibrillation

Address for correspondence: Mouaz H. Al-Mallah, MD, MSc, Associate Professor of Medicine, Consultant Cardiologist and Division Head, Cardiac Imaging, King Abdul-Aziz Cardiac Center, National Guard Health Affairs, Department Mail Code: 1413, P.O. Box 22490, Riyadh 11426, Kingdom of Saudi Arabia, tel: +966118011111, ext. 16594, fax: 16700, e-mail: mouaz74@gmail.com

Received: 12.11.2015 Accepted: 09.03.2016 


\section{Introduction}

Digoxin is commonly used for rate control in atrial fibrillation (AF). Despite a relative paucity of data from large randomized controlled trials, several guidelines have recommended its use. The 2014 American Heart Association/American College of Cardiology guidelines suggest the use of digoxin alone in sedentary patients (class I, level of evidence: C) or in combination with either a beta-blocker or non-dihydropyridine calcium channel blocker for non-sedentary individuals and individuals with heart failure (HF) (class IIA, level of evidence: B) [1]. The European Society of Cardiology also recommends its long-term use in both sedentary and active AF patients (class IIA, level of evidence: C) [2]. However, there is growing controversy regarding the association between digoxin and mortality. Earlier investigations of digoxin in $\mathrm{HF}$ patients did not demonstrate an increased risk of mortality with digoxin use [3]. However, recent studies suggested an increased risk of mortality with digoxin among AF patients $[4,5]$. It will be difficult to design a randomized controlled trial that would evaluate these findings and thus a meta-analysis may provide useful insight and information regarding digoxin use in $\mathrm{AF}$ patients. To evaluate the association of digoxin with mortality in AF, we conducted a systematic review and meta-analysis to assess whether digoxin use in $\mathrm{AF}$ patients is independently associated with an increased risk of mortality.

\section{Methods}

\section{Study design}

Protocol. We undertook a systematic review and meta-analysis of randomized controlled trials and observational studies assessing digoxin use in $\mathrm{AF}$ patients and its association with mortality.

Data collection. Two reviewers performed an electronic search of MEDLINE, EMBASE, GoogleScholar, Web of Science for published manuscripts until December 15, 2014. We reviewed abstracts from major cardiology meetings held between 2001 and 2014. No limits were used for the search. We also searched the references of the related articles, as well as links to related articles to gather additional articles. We also performed an extensive search of the narrative reviews of the relevant topics. The search terms included variants of "atrial fibrillation", "atrial flutter", "atrial arrhythmia", "supraventricular tachycardia”, "digoxin", "digitalis”, "cardiac glycoside”, "digitoxin”, "foxglove”, "mortality”, “death”, “outcomes”, "risk factor”, "clinical trials", and "prognosis" using text words and Medical Subject Headings (MeSH) terms. We also reviewed editorials and letters related to the topic to identify published and unpublished data. There were no restrictions applied to language, publication date, or publication status. The search was performed without any language restrictions. When an abstract from a meeting and a full article referred to the same trial, only the full article was included in the analysis. When there were multiple reports from the same trial, we used the most complete and/or recently reported data.

\section{Inclusion and exclusion criteria}

We included both observational studies and analyses from clinical trials. Randomized controlled trial was defined according to the National Library of Medicine criteria. Atrial fibrillation was defined either by electrocardiogram, self-report or international classification of diseases codes. Studies that did not report mortality were excluded. Data for each trial were abstracted by an investigator (W.T.Q.) and confirmed by a second investigator (M.A.). All discrepancies were identified and resolved by consensus, or as needed, with a third investigator (W.T.O.).

Study quality. We followed the Preferred Reporting Items for Systematic reviews and MetaAnalyses (PRISMA) guidelines for systematic reviews and meta-analyses [6]. We did not use a proper scoring system to grade the study quality as strongly discouraged by the Cochrane Collaboration [7].

Outcomes. The primary endpoint was allcause mortality. The secondary outcome was cardiovascular mortality. Data on endpoints were abstracted by Waquas Qureshi and Mouaz H. Al-Mallah. All disagreements were resolved by reaching consensus.

Statistical analysis. For all studies, we extracted the study baseline characteristics, event rates, hazard ratios (HR), and 95\% confidence intervals (CI) for the primary and secondary outcomes. We extracted HRs for digoxin use in $\mathrm{AF}$ patients and all-cause mortality from published manuscripts and abstracts. The effect sizes were obtained from intention-to-treat analyses and fully adjusted models in the cohort studies.

The primary analysis measured the pooled estimate of mortality risk associated with digoxin use in AF patients. The secondary analysis measured the pooled estimate of risk for cardiovascular mortality. A stratified analysis for individuals with 
and without $\mathrm{HF}$ was also performed as HF patients with $\mathrm{AF}$ are more likely to be treated with digoxin due to its inotropic effect. Since we expected significant heterogeneity in the results, we also performed a pre-specified sensitivity analysis without observational studies.

To study heterogeneity, we hypothesized that the effect size may differ according to methodological quality of the studies. Thus, we used a random effects model by DerSimonian and Laird [8]. The random effects model assumes that the studies included in the meta-analysis are a random sample of hypothetical study populations. The random effects model provides a more conservative estimate of the combined data with a wider confidence interval and the summary statistic is less likely to be significant. The heterogeneity was assessed using the Cochrane $\mathrm{Q}$ statistic and the percentage of total variability due to true-between study heterogeneity was evaluated by using the $\mathrm{I}^{2}$ measure. A p-value $<0.10$ was considered significant for $\mathrm{I}^{2}$ measure and interaction tests [9].

We performed meta-regression to examine if the natural log-transformed HR of the effect of digoxin use on mortality was influenced by the prevalence of HF. We used an unrestricted maximal likelihood method for mixed effects regression to evaluate for slope significance.

We assessed publication bias subjectively by visual inspection of Begg's funnel plot [10] and objectively by Egger's regression asymmetry test as funnel plots may be inaccurate in the assessment of very large studies $[11,12]$. To address the possibility that "N" number of studies possibly were missing from our analysis and these studies, if included in the analysis, would shift the effect size towards the null, we used Orwin's fail-safe $\mathrm{N}$ formula. If the meta-analysis has captured all the relevant studies, then the funnel plot is expected to be symmetrical. However, if there is asymmetry in the plot, it is expected that there are some studies missing from the analysis. This asymmetry is addressed by Duval and Tweedie "trim and fill" method. For example, if there are more studies on the right-hand side and fewer studies on the left-hand side of the funnel plot, this would raise concern that these left-hand studies potentially exist. The Duval and Tweedie trim and fill method trims the right hand asymmetric studies to calculate an unbiased effect by an iterative procedure. It then fills the plot by re-introducing the right hand trimmed studies on the right as well as imputed counterparts to the left of the mean effect [13]. We reported the unbiased effect and the number of possible missing studies from the analysis. We also performed an additional cumulative analysis to evaluate if there was a temporal effect of the studies. Additionally, we evaluated removal of individual studies on the pooled HR. All analyses were performed using RevMan v. 5.0 and Comprehensive Meta-Analysis v. 2.2.4.

\section{Results}

We identified 1,543 studies during the initial literature search. After removing duplicates, 1,242 studies remained. After reading the abstracts and full text of the selected studies, 1,052 studies were discarded due to inability to meet inclusion criteria. Full review of 101 manuscripts and abstracts was performed and 24 studies were selected, 6 did not report the desired HRs and effect sizes to estimate our primary outcome. One of the studies was a patient-level meta-analysis of 4 trials [14]. Finally, 16 studies were selected with study data of 19 studies in this meta-analysis (Suppl. Fig. 1).

As mentioned above, there were 6 studies out of 16 that reported data from 9 clinical trials while other studies were observational in nature. There was 1 conference presentation and 1 conference abstract, while the remaining studies were either published or in online print. We used both of them separately. Study characteristics are presented in Table 1. Studies mainly included males from white populations. Hypertension was the most frequent risk factor (39-100\%) and only 1 study did not include patients with HF.

There were a total of 501,681 participants (mean age 73.8 years, males $62.3 \%$ ), of whom 43,370 were enrolled in clinical trials and 458,311 included in observational studies. There were 414,116 patients with AF. There were 111,978 digoxin users and 389,643 participants who did not use digoxin. A breakdown for each study is presented in Supplementary Table 1.

Using a random effects model, the risk of mortality was $27 \%$ higher in individuals using digoxin compared with persons who did not use digoxin (pooled HR: 1.27; 95\% CI 1.19-1.36, p < 0.001) (Fig. 1). When only subgroups of randomized clinical trials were analyzed, the risk for mortality for digoxin users increased to $46 \%$ (pooled HR: 1.46; 95\% CI 1.09-1.94, $\mathrm{p}=0.01$ ) (Fig. 2). There was a high degree of heterogeneity in pooled studies $\left(\chi^{2}: 124, \mathrm{df}=14, \mathrm{p}<0.001 ; \mathrm{I}^{2}=89 \%\right)$. When only studies with older individuals $(\mathrm{n}=8$; age $>70)$ who had a higher prevalence of $\mathrm{HF}$ ( $>30 \%$ ) were retained in the analysis, the heterogeneity became 
Table 1. Characteristics of the included studies.

\begin{tabular}{|c|c|c|c|c|c|c|c|c|c|}
\hline Study & Year & $\begin{array}{c}\text { Mean } \\
\text { age } \\
\text { [years] }\end{array}$ & $\begin{array}{c}\text { Males } \\
{[\%]}\end{array}$ & $\begin{array}{c}\text { Hypertension } \\
{[\%]}\end{array}$ & $\begin{array}{l}\text { Diabetes } \\
{[\%]}\end{array}$ & $\begin{array}{l}\text { Beta- } \\
\text {-blocker } \\
\text { use [\%] }\end{array}$ & $\begin{array}{c}\text { ACE inhi- } \\
\text { bitor/ARB } \\
\text { use [\%] }\end{array}$ & $\begin{array}{l}\text { HF } \\
{[\%]}\end{array}$ & $\begin{array}{l}\text { IHD } \\
{[\%]}\end{array}$ \\
\hline LIFE [28] & 1997 & 67 & 42 & 100 & 13 & 49 & 50 & 1.4 & 15.3 \\
\hline AFFIRM [15] & 2001 & 70 & 61 & 71 & 20 & 58 & 64 & 8.2 & 38.1 \\
\hline SPORTIF [29] & 2002 & 71 & 69 & 77 & 24 & 4 & NA & 36.6 & 44.7 \\
\hline RIKS-HIA [4] & 2003 & 68 & 58 & 39 & 25 & 50 & 35 & 37.8 & 55.9 \\
\hline SCAF [5] & 2007 & 77 & 55 & 48 & 18 & 50 & 38 & 44.7 & 19.1 \\
\hline Fauchier [23] & 2007 & 74 & 61 & 45 & 17 & 35 & 73 & 43 & 23 \\
\hline TREAT-AF [30] & 2008 & 72 & 98 & 63 & 29 & NA & NA & 15.6 & 4.5 \\
\hline ATRIA-CVRN [24] & 2009 & 71 & 56 & 78 & 24 & 58 & 44 & 0 & 3.7 \\
\hline RACE II [31] & 2009 & 68 & 66 & 61 & 11 & 70 & 51 & 34.5 & 17.9 \\
\hline ROCKET-AF [32] & 2010 & 73 & 60 & 90 & 40 & 65 & 67 & 54.4 & 23.3 \\
\hline NHIRD [33] & 2010 & 67 & 54 & 66 & 30 & NA & NA & 10.9 & 10.1 \\
\hline PALLAS [34] & 2010 & 75 & 65 & 85 & NA & 41 & 77 & 54 & 41 \\
\hline ADONIS [14] & 2010 & 64 & 69 & 54 & NA & 65 & 41 & 12.2 & 24.2 \\
\hline ANDROMEDA [14] & 2010 & 72 & 79 & 39 & NA & 71 & 83 & 100 & 63.3 \\
\hline ATHENA [14] & 2010 & 72 & 53 & 86 & NA & 74 & 70 & 21.2 & 30 \\
\hline ORBIT-AF [35] & 2011 & 68 & 57 & NA & NA & NA & NA & 13 & 16 \\
\hline Quebec study [27] & 2012 & 80 & 42 & 62 & 32 & 51 & 61 & 32.3 & NA \\
\hline AUPD study [36] & 2012 & 73 & 53 & 20 & 8 & 18 & NA & 10 & 9.4 \\
\hline Pastori study [37] & 2013 & 73 & 57 & 89 & 20 & 41 & 70 & 16 & 23 \\
\hline
\end{tabular}

ACE/ARB - angiotensin converting enzyme/angiotensin receptor blocker; HF — heart failure; IHD — ischemic heart disease; NA — not available; LIFE - The Losartan Intervention For Endpoint reduction in hypertension; AFFIRM - the AF Follow-Up Investigation of Rhythm Management; SPORTIF - the Stroke Prevention using an ORal Thrombin Inhibitor in atrial Fibrillation; RIKS-HIA - the Registry of Information and Knowledge about Swedish Heart Intensive care Admissions; SCAF — the Stockholm Cohort-Study of Atrial Fibrillation; TREAT-AF - The Retrospective Evaluation and Assessment of Therapies in AF); ATRIA-CVRN - the AnTicoagulation and Risk factors In Atrial fibrillation-Cardiovascular Research Network; RACE II — Rate Control Efficacy in Permanent AF; ROCKET-AF — the rivaroxaban once daily, oral, direct factor Xa inhibition compared with vitamin $\mathrm{K}$ antagonism for prevention of stroke and embolism trial in atrial fibrillation; NHIRD —- the National Health Insurance Research Database; PALLAS - The Permanent Atrial FibriLLation Outcome Study using dronedarone on top of standard therapy; ADONIS - The American-Australian-African trial with DronedarONe In atrial fibrillation or flutter Patients for the maintenance of Sinus rhythm; ANDROMEDA - the ANtiarrhythmic trial with DROnedarone in Moderate-to-severe CHF Evaluating morbidity DecreAse; ATHENA A placebo-controlled, double-blind, parallel arm Trial to assess the efficacy of dronedarone 400 mg b.i.d. for the prevention of cardiovascular Hospitalization or death from any cause in patiENts with Atrial fibrillation/atrial flutter; ORBIT-AF - the Outcomes Registry for Better Informed Treatment of Atrial Fibrillation; AUPD — Aarhus University Prescription Database

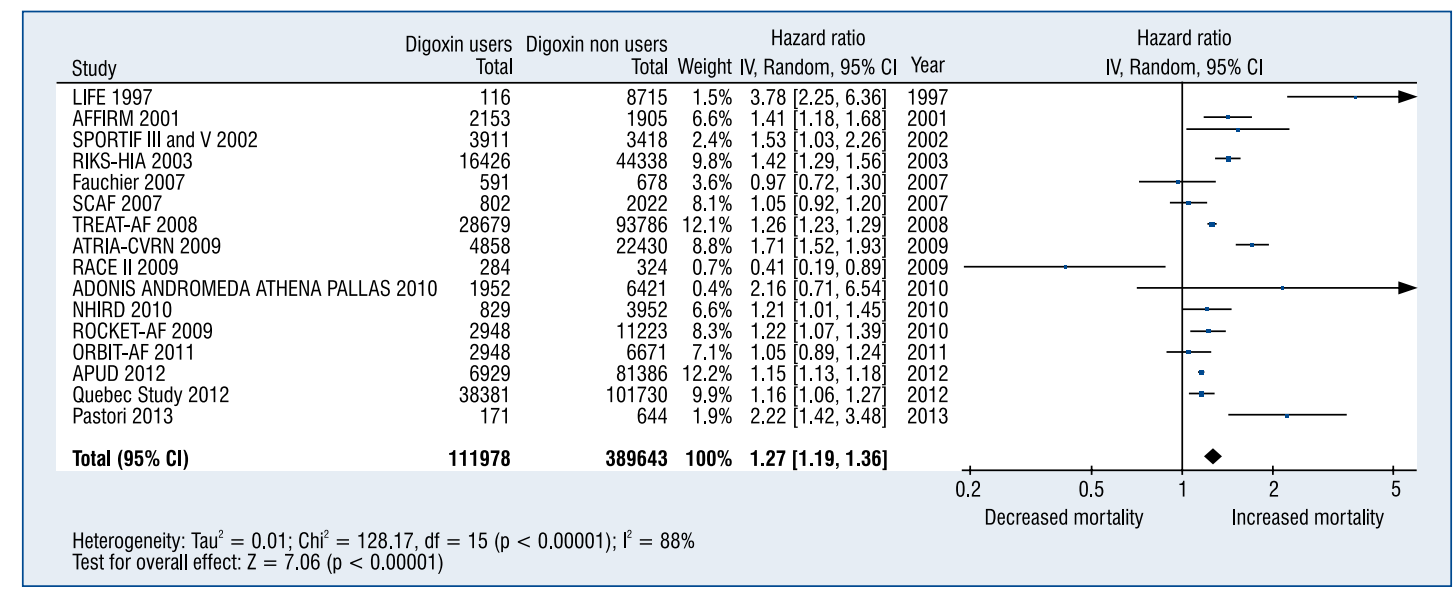

Figure 1. Forest plot of the included studies. The computed weighted hazard ratios are depicted as boxes proportional to the size of the study. The bars depict the $95 \%$ confidence intervals (CI). Studies favoring use of digoxin are on the right hand side of the center line of no effect, while the studies against the use of digoxin are on the left hand side of the center line of no effect. 


\begin{tabular}{|c|c|c|c|c|c|c|c|c|}
\hline \multirow{2}{*}{$\begin{array}{l}\text { Study of subgroup } \\
\text { SPORTIF III and V } 2002 \\
\text { ROCKET-AF } 2009 \\
\text { RACE II } 2009 \\
\text { LIFE } 1997 \\
\text { AFFIRM } 2001 \\
\text { ADONIS ANDROMEDA ATHENA PALLAS } 2010\end{array}$} & $\begin{array}{r}\text { Digoxin users } \\
\text { Total }\end{array}$ & \multicolumn{2}{|c|}{ Non digoxin users } & $\begin{array}{c}\text { Hazard ratio } \\
\text { IV, Random, } 95 \% \mathrm{CI}\end{array}$ & \multicolumn{3}{|c|}{$\begin{array}{c}\text { Hazard ratio } \\
\text { IV, Random, } 95 \% \mathrm{CI}\end{array}$} & \\
\hline & $\begin{array}{r}3911 \\
2948 \\
284 \\
116 \\
2153 \\
1952\end{array}$ & $\begin{array}{r}3418 \\
11223 \\
324 \\
8715 \\
1905 \\
6421\end{array}$ & $\begin{array}{r}22.6 \% \\
24.8 \% \\
9.1 \% \\
14.1 \% \\
24.1 \% \\
5.3 \%\end{array}$ & $\begin{array}{l}1.53[1.22,1.92] \\
1.22[1.06,1.40] \\
0.41[0.19,0.89] \\
3.78[2.25,6.36] \\
1.41[1.19,1.67] \\
2.16[0.71,6.54]\end{array}$ & & & $\because$ & \\
\hline Total $(95 \%$ Cl) & 11364 & 32006 & $100.0 \%$ & $1.46[1.09,1.94]$ & & & & \\
\hline $\begin{array}{l}\text { Heterogeneity: } \text { Tau }^{2}=0.08 ; \mathrm{Chi}^{2}=28.43, \mathrm{df}= \\
\text { Test for overall effect: } \mathrm{Z}=2.57(\mathrm{p}=0.01)\end{array}$ & $=5(p<0.0 c$ & $001) ; l^{2}=$ & & & 0.2 & $\begin{array}{c}0.5 \\
\text { Decreased mortality }\end{array}$ & Ir & $\begin{array}{lr}2 & 5 \\
\text { Increased mortality }\end{array}$ \\
\hline
\end{tabular}

Figure 2. Forest plot of subgroup analyses of randomized controlled clinical trials (sensitivity analysis). The computed weighted hazard ratios are depicted as boxes proportional to the size of the study. The bars depict the $95 \%$ confidence intervals (Cl). Studies favoring use of digoxin are on the right hand side of the center line of no effect, while the studies against the use of digoxin are on the left hand side of the center line of no effect.

insignificant $\left(\chi^{2}: 7.10, \mathrm{df}=6, \mathrm{p}=0.31 ; \mathrm{I}^{2}=16 \%\right)$. The AF Follow-Up Investigation of Rhythm Management (AFFIRM) trial had 2 published analyses. For primary analysis, we used the study with the larger subsample [15], however in a sensitivity analysis with the smaller sub-study [16], there was no significant difference in the pooled HRs (1.27; 95\% CI $1.19-1.36$ vs. 1.20 ; 95\% CI 1.18-1.22, $\mathrm{p}$ for interaction $=0.11$ ). Other subgroup analyses are shown in Supplementary Table 2. The risk of cardiovascular mortality associated with digoxin use was available in 9 studies. In a random effects model, digoxin use was associated with a $21 \%$ increased risk of mortality (pooled HR: $1.21 ; 95 \% \mathrm{CI}$ $1.12-1.30, \mathrm{p}<0.001$ ) with significant inter-study heterogeneity $\left(\mathrm{I}^{2}=74 \%, \mathrm{p}<0.001\right)$ (Suppl. Fig. 2). Removal of studies with $<30 \%$ of HF showed no heterogeneity $(\mathrm{p}>0.1)$.

In a stratified analysis, the risk of mortality for individuals using digoxin in $\mathrm{AF}$ patients with HF was $21 \%$ higher (pooled HR: $1.21 ; 95 \%$ CI $1.07-1.36, p=0.002$; Fig. $3 \mathrm{~A}$ ) compared with participants who did not use digoxin. The risk of mortality for individuals without $\mathrm{HF}$ was $47 \%$ higher for digoxin users (pooled HR: 1.47; 95\% CI 1.25-1.73, $\mathrm{p}<0.001$; Fig. 3B) than non-digoxin users.

Due to heterogeneity, a funnel plot was created to assess publication bias (Suppl. Fig. 3). The funnel plot showed minimal asymmetry that was quantified statistically by Egger's regression intercept (intercept: 1.16 ; 95\% CI $-0.76-3.08$, $\mathrm{df}=14$, 1-tailed p-value: 0.11$)$. Classical fail safe $\mathrm{N}$ was 1507 , suggesting that there would need to be 1507 null studies with mean HR of 1.00 added to the analysis before the pooled effect would become non-significant. A more conservative method, Orwin's fail-safe $\mathrm{N}$ method was used to estimate the number of studies that would need to be added to the meta-analysis to make the pooled effect nonsignificant. For this reason, we assumed a mean HR of less than 0.90 for the potentially missing studies. Using this criterion, at least 29 studies would be needed to make the association between digoxin use and mortality non-significant. Using a trim and fill method, we needed to trim a study on the left of the mean which changed the pooled estimate from 1.28 (95\% CI 1.20-1.37) to 1.26 (95\% CI 1.18-1.35). There was no asymmetry on the right of the mean.

Additional analyses showed that there was a temporal effect present with more recent studies having lower effect sizes than older studies, however the direction and point estimate for the pooled HRs remained significant (Suppl. Fig. 4). When we removed one study from the analysis at each step of the analysis, the pooled estimate remained significant (Suppl. Fig. 5). In meta-regression analysis, proportion of $\mathrm{HF}$ in studies was inversely associated with risk of mortality associated with digoxin (slope: -0.008 ; $95 \%$ CI from -0.01 to $-0.002, \mathrm{p}=0.02$, Suppl. Fig. 6) suggesting HF modifies the risk of mortality and digoxin use.

\section{Discussion}

This comprehensive meta-analysis included 501,681 individuals and assessed the effect of digoxin use in AF patients in 9 randomized clinical trials and 10 observational cohorts. There were three main findings: 1) digoxin users with AF had a $27 \%$ increased risk of all-cause mortality, 2) digoxin users with $\mathrm{AF}$ had a $21 \%$ increased risk of cardiovascular mortality, and 3) digoxin users with $\mathrm{AF}$ who did not have HF had a relatively stronger association with risk of all-cause mortality (47\% vs. $21 \%, p$ for interaction $=0.058$ ) than digoxin users with HF. 


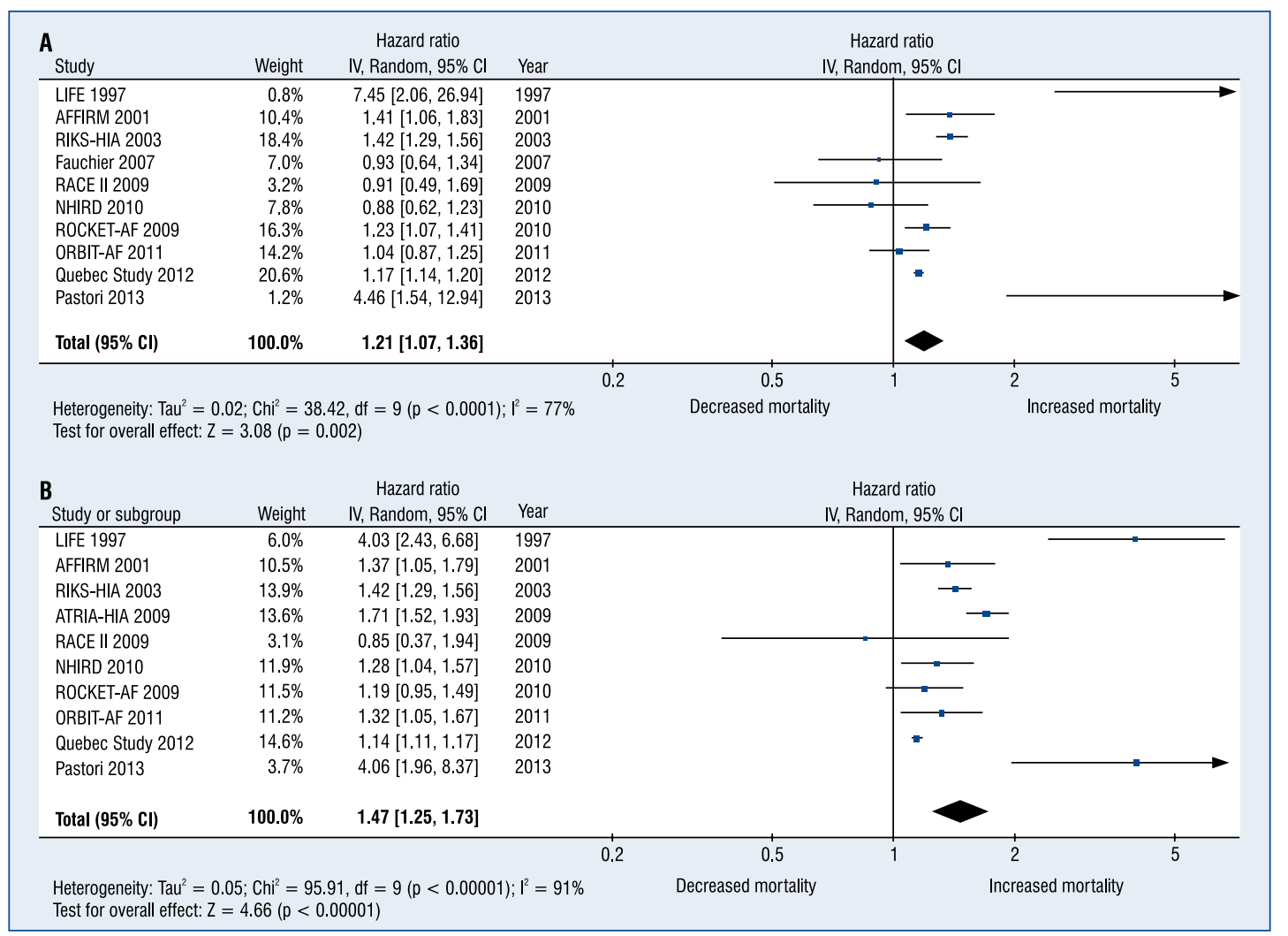

Figure 3. Forest plot of studies including atrial fibrillation patients with heart failure showing association of digoxin use with all-cause mortality. The computed weighted hazard ratios are depicted as boxes proportional to the size of the study. The bars depict the $95 \%$ confidence intervals $(\mathrm{Cl})$. Studies favoring use of digoxin are on the right hand side of the center line of no effect, while the studies against the use of digoxin are on the left hand side of the center line of no effect; A. Heterogeneity becomes insignificant after removing, LIFE, RIKS-HIA, RACE-II and Pastori study, $\mathrm{I}^{2}=40 \%, \mathrm{p}=0.14$; B. Heterogeneity becomes insignificant after removing, LIFE, ATRIA-CVRN, RIKS-HIA and Pastori study, $\mathrm{I}^{2}=1 \%, \mathrm{p}=0.41$.

Several reports have examined the negative consequences of digoxin use resulting in a significant drop in digoxin use in acute myocardial infarction during the last two decades [17, 18]. Data supporting its use in chronic systolic HF have mainly come from two withdrawal studies [19,20], and the Digitalis Investigation Group trial that showed an absolute increase of $1.9 \%$ in cardiac death with digitalis (not including HF-related death) [21]. However, due to concomitant absolute reduction in HF-related mortality by $1.6 \%$, the overall primary endpoint was not significant.

The aforementioned studies found an increased risk of all-cause mortality in conditions that are not limited to AF. Our results support these prior findings and extend prior work to show an increased risk of all-cause and cardiovascular mortalities exist for $\mathrm{AF}$ patients who use digoxin. Although the risks for the adverse outcomes examined were attenuated when we examined patients with $\mathrm{HF}$, there was still a suggestion of $21 \%$ increased risk of all-cause mortality in these patients.

We also observed a downward temporal trend in reduced risk of mortality associated with digoxin use over the last 15 years. The reason for this difference is speculative but possibly related to the improved management of cardiovascular disease over the last decade [22]. Several of these studies have included individuals over periods of time, and have found a decreasing trend towards reduced prescription of digoxin by the clinicians [23].

The exact mechanism underlying increased mortality risk observed with digoxin is unknown. Most of the reviewed studies did not evaluate the serum digoxin levels with mortality. Serum digoxin levels were significantly higher in those who died (1.151 vs. $0.935 \mathrm{ng} / \mathrm{mL}, \mathrm{p}<0.001)$ in one of the studies [24]. Renal function regulates serum digoxin levels and a subgroup analysis of AF-FIRM demonstrated increased mortality in digoxin 
users (HR: 1.28; 95\% CI 1.25-1.31; p < 0.001). Thus it can be speculated that higher serum levels of digoxin are related with the pathogenesis. Sudden cardiac death was also observed to be high in ROCKET-AF study and LIFE study in digoxin users. Sudden cardiac death is frequently due to fatal arrhythmia [25]. Digoxin was shown to increase arrhythmia-related deaths by $61 \%$ in post hoc analysis of AFFIRM trial [15]. Furthermore, we identified association of digoxin with cardiovascular mortality as well suggesting this observed mortality has cardiac basis rather than non-cardiovascular cause. This has been also previously demonstrated in a study without patients with AF [15]. Digoxin was shown to increase arrhythmia-related deaths by $61 \%$ in post hoc analysis of AFFIRM trial [15].

This study has several implications regarding management of $\mathrm{AF}$ in patients with and without $\mathrm{HF}$. The burden of $\mathrm{AF}$ is increasing at dramatic pace with doubling AF by 2050 . The annual mortality risk in $\mathrm{AF}$ is $3.84 \%$, of which $37.4 \%$ occur due to cardiovascular conditions [26]. This analysis shows that at least $1 / 4^{\text {th }}$ of this risk is probably related to digoxin. A possible reduction in prescription of digoxin to these individuals may potentially improve overall survival of these patients. Even though the results have been consistent, this study still is limited by its exploratory design and thus calls for a randomized trial of digoxin in $\mathrm{AF}$ patients, with and without HF, to demonstrate its safety. However, it may be difficult to perform a randomized study at this point; a withdrawal study might be more suitable to confirm our findings. Additionally, this study suggests that there is a need to revisit the management guidelines of AF. There have been several changes in the management of $\mathrm{HF}$ and $\mathrm{AF}$ in the last decade. Management of AF in the light of recent evidence-based therapies may eventually lead to discarding the use of digoxin in these particular patients.

\section{Limitations of the study}

The current analysis should be interpreted in the context of several limitations. We did not have access to the source data for any of the studies used and the analysis was based on effect sizes and confidence intervals obtained from published studies. There was a significant heterogeneity in the population which remained unexplained and possibly is due to differences in the study samples examined. Also, the included studies from clinical trials were performed as post hoc analyses and potentially introduced bias into the current study. Bias by indication also is a significant limitation that should be considered while interpreting these results. Additionally, we were not able to assess the type of AF (e.g., paroxysmal, persistent, permanent) and the results may vary when accounting for this aspect of the arrhythmia. The exact doses of digoxin and other $\mathrm{AF}$ medications were unknown and possibly influenced the relationship between digoxin and the outcomes examined (e.g., drug-drug interactions) [27].

\section{Conclusions}

The results from this pooled analysis suggest that digoxin use in $\mathrm{AF}$ is associated with an increased risk of all-cause and cardiovascular mortalities. Special consideration should be used by clinicians who use digoxin for rate control in patients with AF. Further study is needed to elucidate the underlying mechanism related to the increased risk of adverse events associated with digoxin.

\section{Conflict of interest: None declared}

\section{References}

1. January CT, Wann LS, Alpert JS et al. 2014 AHA/ACC/HRS Guideline for the Management of Patients With Atrial Fibrillation: A Report of the American College of Cardiology/American Heart Association Task Force on Practice Guidelines and the Heart Rhythm Society. Circulation, 2014; 130: e272.

2. Camm AJ, Kirchhof P, Lip GY et al. Guidelines for the management of atrial fibrillation: the Task Force for the Management of Atrial Fibrillation of the European Society of Cardiology (ESC). Eur Heart J, 2010; 31: 2369-2429.

3. Ahmed A, Rich MW, Fleg JL et al. Effects of digoxin on morbidity and mortality in diastolic heart failure: the ancillary digitalis investigation group trial. Circulation, 2006; 114: 397-403.

4. Hallberg P, Lindback J, Lindahl B, Stenestrand U, Melhus H. Digoxin and mortality in atrial fibrillation: a prospective cohort study. Eur J Clin Pharmacol, 2007; 63: 959-971.

5. Friberg L, Hammar N, Pettersson H, Rosenqvist M. Increased mortality in paroxysmal atrial fibrillation: Report from the Stockholm Cohort-Study of Atrial Fibrillation (SCAF). Eur Heart J, 2007; 28: 2346-2353.

6. Moher D, Liberati A, Tetzlaff J, Altman DG. Preferred reporting items for systematic reviews and meta-analyses: The PRISMA statement. PLoS Med, 2009; 6: e1000097.

7. Cochrane handbook for systematic reviews of interventions. 2009. (Accessed at http://handbook.cochrane.org/chapter_8/8_3_3_quality_scales_and_cochrane_reviews.htm).

8. DerSimonian R, Laird N. Meta-analysis in clinical trials. Controlled Clin Trials 1986; 7: 177-88.

9. Higgins JP, Thompson SG, Deeks JJ, Altman DG. Measuring inconsistency in meta-analyses. BMJ, 2003; 327: 557-560.

10. Egger M, Davey Smith G, Schneider M, Minder C. Bias in meta-analysis detected by a simple, graphical test. BMJ, 1997; 315: 629-634.

11. Moreno SG, Sutton AJ, Ades AE et al. Assessment of regressionbased methods to adjust for publication bias through a comprehensive simulation study. BMC Medical Research Methodology, 2009; 9: 2.

12. HunterJP, Saratzis A, Sutton AJ, Boucher RH, Sayers RD, Bown MJ. In meta-analyses of proportion studies, funnel plots were 
found to be an inaccurate method of assessing publication bias. J Clin Epidemiol, 2014; 67: 897-903.

13. Duval S TR. A nonparametric "trim and fi ll" method of assessing publication bias in meta-analysis. J Am Statistical Assoc, 2000; 95: 89-98.

14. Hohnloser SH, Connolly SJ, John Camm A, Halperin JL, Radzik D. An individual patient-based meta-analysis of the effects of dronedarone in patients with atrial fibrillation. Europace, 2014; 16: 1117-1124.

15. Whitbeck MG, Charnigo RJ, Khairy P et al. Increased mortality among patients taking digoxin: Analysis from the AFFIRM study. Eur Heart J, 2013; 34: 1481-1488.

16. Gheorghiade M, Fonarow GC, van Veldhuisen DJ et al. Lack of evidence of increased mortality among patients with atrial fibrillation taking digoxin: Findings from post hoc propensity-matched analysis of the AFFIRM trial. Eur Heart J, 2013; 34: 1489-1497.

17. Leor J, Goldbourt U, Rabinowitz B et al. Digoxin and increased mortality among patients recovering from acute myocardial in farction: Importance of digoxin dose. The SPRINT Study Group. Cardiovasc Drugs Therapy, 1995; 9: 723-729.

18. Kober L, Torp-Pedersen C, Gadsboll N, Hildebrandt P, Hoilund-Carlsen PF. Is digoxin an independent risk factor for long-term mortality after acute myocardial infarction? Eur Heart J, 1994; 15: 382-388.

19. Uretsky BF, Young JB, Shahidi FE, Yellen LG, Harrison MC, Jolly MK. Randomized study assessing the effect of digoxin withdrawal in patients with mild to moderate chronic congestive heart failure: Results of the PROVED trial. PROVED Investigative Group. J Am Coll Cardiol, 1993; 22: 955-962.

20. Packer M, Gheorghiade M, Young JB et al. Withdrawal of digoxin from patients with chronic heart failure treated with angiotensin-converting-enzyme inhibitors. RADIANCE Study. New Engl J Med, 1993; 329: 1-7.

21. Digitalis Investigation Group. The effect of digoxin on mortality and morbidity in patients with heart failure. New Engl J Med, 1997; 336: 525-533.

22. Go AS, Mozaffarian D, Roger VL et al. Executive summary: Heart disease and stroke statistics, 2014 update: A report from the American Heart Association. Circulation, 2014; 129: 399-410.

23. Fauchier L, Grimard C, Pierre B et al. Comparison of beta blocker and digoxin alone and in combination for management of patients with atrial fibrillation and heart failure. Am J Cardiol, 2009; 103: 248-254.

24. Freeman JV, Reynolds K, Fang M et al. Digoxin and risk of death in adults with atrial fibrillation: The ATRIA-CVRN Study. Circulation, 2015 ; 8: 49-58.
25. Tung P, Albert CM. Causes and prevention of sudden cardiac death in the elderly. Nature Rev Cardiol, 2013; 10: 135-142.

26. Marijon E, Le Heuzey JY, Connolly S et al. Causes of death and influencing factors in patients with atrial fibrillation: A competing-risk analysis from the randomized evaluation of long-term anticoagulant therapy study. Circulation, 2013; 128: 2192-2201.

27. Shah M, Avgil Tsadok M, Jackevicius CA, Essebag V, Behlouli H Pilote L. Relation of digoxin use in atrial fibrillation and the risk of all-cause mortality in patients $>/=65$ years of age with versus without heart failure. Am J Cardiol, 2014; 114: 401-406.

28. Okin PM, Bang CN, Wachtell K et al. Relationship of sudden cardiac death to new-onset atrial fibrillation in hypertensive patients with left ventricular hypertrophy. Circulation, 2013; 6: 243-251.

29. Gjesdal K, Feyzi J, Olsson SB. Digitalis: A dangerous drug in atrial fibrillation? An analysis of the SPORTIF III and V data. Heart, 2008; 94: 191-196.

30. Turakhia MP, Santangeli P, Winkelmayer WC et al. Increased mortality associated with digoxin in contemporary patients with atrial fibrillation: Findings from the TREAT-AF study. J Am Coll Cardiol, 2014; 64: 660-668.

31. Mulder BA, Van Veldhuisen DJ, Crijns HJ et al. Digoxin in patients with permanent atrial fibrillation: Data from the RACE II study. Heart Rhythm, 2014; 11: 1543-1550.

32. Washam JB, Lokhnygina Y, Halperin JL et al. Digoxin use in patients with atrial fibrillation is associated with adverse cardiovascular outcomes: Results from the ROCKET AF trial. European Society of Cardiology Annual Sessions. Barcelona, Spain 2014: 4873.

33. Chao TF, Liu CJ, Chen SJ et al. Does digoxin increase the risk of ischemic stroke and mortality in atrial fibrillation? A nationwide population-based cohort study. Canadian J Cardiol, 2014; 30: 1190-1195.

34. Hohnloser SH, Halperin JL, Camm AJ, Gao P, Radzik D, Connolly SJ. Interaction between Digoxin and Dronedarone in the PALLAS Trial. Circulation, 2014; 7: 1019-1025.

35. Allen LA, Holmes DN, Thomas LE et al. Digoxin use and subsequent outcomes among patients with and without heart failure in a contemporary atrial fibrillation cohort: Outcomes Registry for Better Informed Treatment of Atrial Fibrillation (ORBIT-AF). Circulation, 2014; 130: e16889.

36. Gamst J, Christiansen CF, Rasmussen BS, Rasmussen LH, Thomsen RW. Pre-existing atrial fibrillation and risk of arterial thromboembolism and death following pneumonia: A populationbased cohort study. BMJ, open 2014; 4: e006486.

37. Pastori D, Farcomeni A, Bucci T et al. Digoxin treatment is associated with increased total and cardiovascular mortality in anticoagulated patients with atrial fibrillation. Int J Cardiol, 2014; 180C: 1-5. 


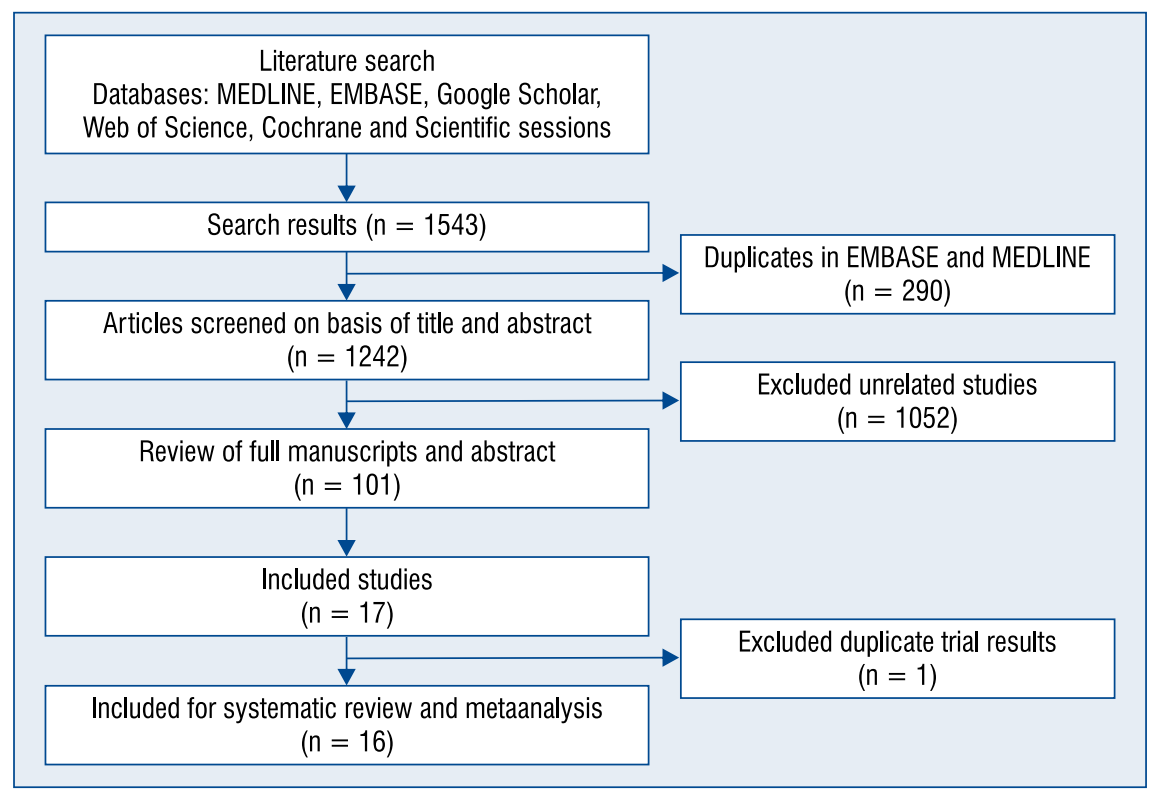

Supplementary Figure 1. Flowchart of the included studies.

Supplementary Table 1. Number of participants in the clinical studies and follow-up duration.

\begin{tabular}{lccccccc}
\hline Study & Year & $\begin{array}{c}\text { Digoxin } \\
\text { users }\end{array}$ & $\begin{array}{c}\text { Non digoxin } \\
\text { users }\end{array}$ & $\begin{array}{c}\text { Atrial } \\
\text { fibrillation }\end{array}$ & Deaths & Total & Follow-up \\
\hline LIFE [28] & 1997 & 116 & 8,715 & 701 & 151 & 8,831 & 4.7 years \\
AFFIRM [15] & 2001 & 2,153 & 1,905 & 4,058 & 666 & 4,058 & 3.5 years \\
SPORTIF [29] & 2002 & 3,911 & 3,418 & 7,329 & 396 & 7,329 & 1.5 years \\
RIKS-HIA [4] & 2003 & 16,426 & 44,338 & 60,764 & 7,520 & 60,764 & 1 years \\
SCAF [5] & 2007 & 802 & 2,022 & 2,824 & 1,038 & 2,824 & 4.6 years \\
Fauchier [23] & 2007 & 591 & 678 & 1,269 & 247 & 1,269 & 881 days \\
TREAT-AF [30] & 2008 & 28,679 & 93,786 & 122,465 & 28,723 & 122,465 & 0.4 years \\
ATRIA-CVRN [24] & 2009 & 4,858 & 22,430 & 27,288 & 1,140 & 27,288 & 1.17 years \\
RACE II [31] & 2009 & 284 & 324 & 608 & 76 & 608 & 3 years \\
ROCKET-AF [32] & 2010 & 2,948 & 11,223 & 14,171 & 1,214 & 14,171 & 3 years \\
NHIRD [33] & 2010 & 829 & 3,952 & 3,952 & 170 & 4,781 & 2.3 years \\
PALLAS [34] & 2010 & 1,070 & 2,166 & 3,236 & 31 & 3,236 & 117 days \\
ADONIS [14] & 2010 & 118 & 511 & 629 & 13 & 629 & 370 days \\
ANDROMEDA [14] & 2010 & 135 & 105 & 240 & 17 & 240 & 228 days \\
ATHENA [14] & 2010 & 629 & 3,639 & 4,268 & 153 & 4,268 & 651 days \\
ORBIT-AF [35] & 2011 & 2,948 & 6,671 & 9,619 & 178 & 9,619 & 3 years \\
Quebec study [27] & 2012 & 38,381 & 101,730 & 140,111 & 79,312 & 140,111 & 3 years \\
AUPD study [36] & 2012 & 6,929 & 81,386 & 8,880 & 12,826 & 88,315 & 365 days \\
Pastori study [37] & 2013 & 171 & 644 & 815 & 85 & 815 & 33.2 months \\
\hline
\end{tabular}

LIFE - The Losartan Intervention For Endpoint reduction in hypertension; AFFIRM — the AF Follow-Up Investigation of Rhythm Management; SPORTIF — the Stroke Prevention using an ORal Thrombin Inhibitor in atrial Fibrillation; RIKS-HIA - the Registry of Information and Knowledge about Swedish Heart Intensive care Admissions; SCAF - the Stockholm Cohort-Study of Atrial Fibrillation; TREAT-AF - The Retrospective Evaluation and Assessment of Therapies in AF); ATRIA-CVRN - the AnTicoagulation and Risk factors In Atrial fibrillation-Cardiovascular Research Network; RACE II - Rate Control Efficacy in Permanent AF; ROCKET-AF - the rivaroxaban once daily, oral, direct factor Xa inhibition compared with vitamin K antagonism for prevention of stroke and embolism trial in atrial fibrillation; NHIRD - the National Health Insurance Research Database; PALLAS - The Permanent Atrial FibriLLation Outcome Study using dronedarone on top of standard therapy; ADONIS - The American-Australian-African trial with DronedarONe In atrial fibrillation or flutter Patients for the maintenance of Sinus rhythm; ANDROMEDA - the ANtiarrhythmic trial with DROnedarone in Moderate-to-severe CHF Evaluating morbidity DecreAse; ATHENA A placebo-controlled, double-blind, parallel arm Trial to assess the efficacy of dronedarone $400 \mathrm{mg}$ b.i.d for the prevention of cardiovascular Hospitalization or death from any cause in patiENts with Atrial fibrillation/atrial flutter; ORBIT-AF - the Outcomes Registry for Better Informed Hospitalization or death from any cause in patiENts with Atrial fibrillation/atrial flutter
Treatment of Atrial Fibrillation; AUPD - Aarhus University Prescription Database 
Supplementary Table 2. Subgroup analyses by various characteristics of studies.

\begin{tabular}{|c|c|c|c|c|c|c|}
\hline \multirow[b]{2}{*}{ Age } & \multicolumn{2}{|c|}{$\begin{array}{c}\text { Risk of mortality } \\
\text { Hazard ratio }(95 \% \mathrm{CI})\end{array}$} & \multicolumn{3}{|c|}{$\begin{array}{c}\text { Risk of cardiovascular mortality } \\
\text { Hazard ratio }(95 \% \mathrm{CI})\end{array}$} & \multirow{2}{*}{$\begin{array}{c}* \\
0.34\end{array}$} \\
\hline & $\begin{array}{c}>70: \\
1.20(1.18-1.21)\end{array}$ & $\begin{array}{c}\leq 70: \\
1.33(1.24-1.42)\end{array}$ & 0.003 & $\begin{array}{c}>70: \\
1.17(1.05-1.30)\end{array}$ & $\begin{array}{c}\leq 70: \\
1.26(1.13-1.41)\end{array}$ & \\
\hline Follow up & $\begin{array}{c}>2 \text { years: } \\
1.22(1.17-1.28)\end{array}$ & $\begin{array}{c}\leq 2 \text { years: } \\
1.20(1.18-1.22)\end{array}$ & 0.67 & $\begin{array}{c}>2 \text { years: } \\
1.21(1.12-1.31)\end{array}$ & $\begin{array}{c}\leq 2 \text { years: } \\
1.20(0.88-1.63)\end{array}$ & 0.05 \\
\hline BB use & $\begin{array}{c}>50 \%: \\
1.21(1.13-1.29)\end{array}$ & $\begin{array}{c}\leq 50 \%: \\
1.20(1.18-1.22)\end{array}$ & 0.22 & $\begin{array}{c}>\mathbf{5 0} \%: \\
1.20(1.10-1.30)\end{array}$ & $\begin{array}{c}\leq 50 \%: \\
1.33(1.06-1.68)\end{array}$ & 0.44 \\
\hline Year 2010 & $\begin{array}{c}\text { During and after: } \\
1.16(1.14-1.18)\end{array}$ & $\begin{array}{c}\text { Before: } \\
1.28(1.25-1.30)\end{array}$ & $<0.001$ & $\begin{array}{c}\text { During and after: } \\
1.23(1.11-1.37)\end{array}$ & $\begin{array}{c}\text { Before: } \\
1.18(1.06-1.32)\end{array}$ & 0.59 \\
\hline IHD & $\begin{array}{c}>20 \%: \\
1.36(1.27-1.45)\end{array}$ & $\begin{aligned} & \leq 20: \\
1.19 & (1.18-1.21)\end{aligned}$ & $<0.001$ & $\begin{array}{c}>20 \%: \\
1.29(1.15-1.44)\end{array}$ & $\begin{array}{c}\leq 20 \%: \\
1.16(1.04-1.28)\end{array}$ & 0.17 \\
\hline HF & $\begin{array}{c}>20 \%: \\
1.22(1.16-1.28)\end{array}$ & $\begin{array}{c}\leq 20 \%: \\
1.20(1.18-1.22)\end{array}$ & 0.54 & $\begin{array}{c}>20 \%: \\
1.21(1.11-1.33)\end{array}$ & $\begin{array}{c}\leq 20 \%: \\
1.20(1.05-1.37)\end{array}$ & 0.92 \\
\hline DM & $\begin{array}{c}>25 \%: \\
1.25(1.23-1.28)\end{array}$ & $\begin{array}{c}\leq 25 \%: \\
1.17(1.16-1.19)\end{array}$ & $<0.001$ & $\begin{array}{c}>25 \%: \\
1.23(1.13-1.35)\end{array}$ & $\begin{array}{c}\leq 25 \%: \\
1.12(0.97-1.30)\end{array}$ & 0.28 \\
\hline Trails & $\begin{array}{l}\text { Clinical only: } \\
1.28(1.16-1.42)\end{array}$ & $\begin{array}{c}\text { Observations only: } \\
1.20(1.18-1.21)\end{array}$ & 0.21 & $\begin{array}{l}\text { Clinical only: } \\
1.20(1.07-1.36)\end{array}$ & $\begin{array}{c}\text { Observations only: } \\
1.21(1.10-1.34)\end{array}$ & 0.92 \\
\hline
\end{tabular}

*P value for interaction; $\mathrm{BB}$ - beta-blocker; $\mathrm{Cl}$ — confidence interval; $\mathrm{DM}$ - diabetes mellitus; HF — heart failure; IHD — ischemic heart disease

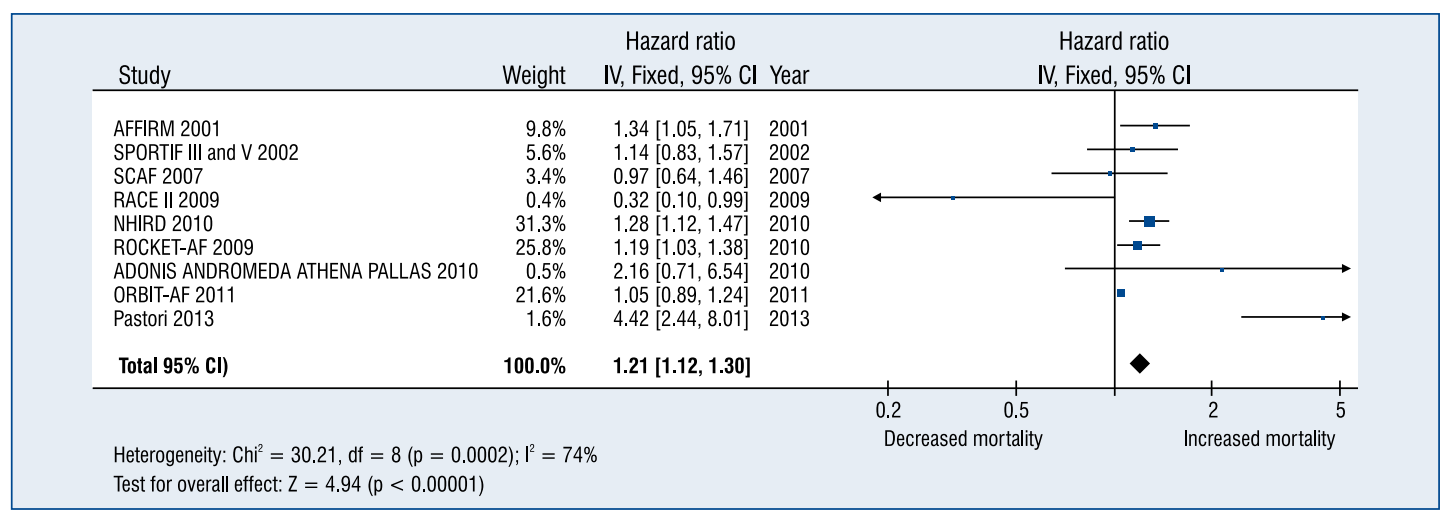

Supplementary Figure 2. Random effects model showing risk of cardiovascular disease with digoxin use ( $\mathrm{n}=9$ studies).

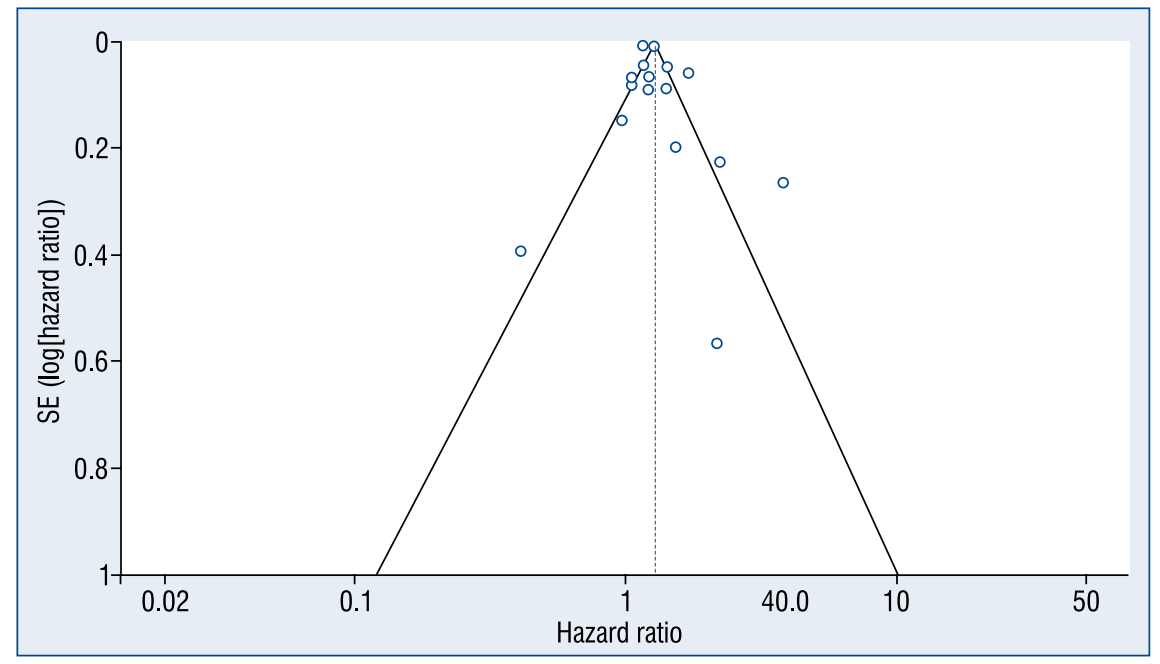

Supplementary Figure 3. Funnel plot showing publication bias. 


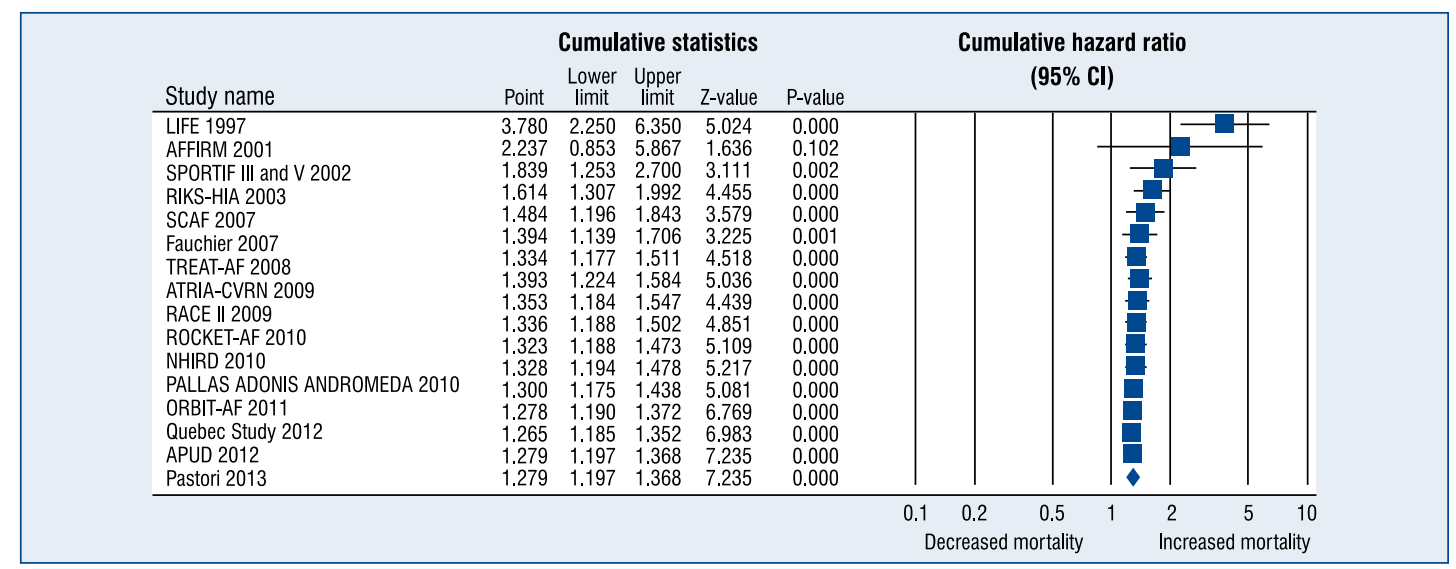

Supplementary Figure 4. Temporal effect shown by point estimates with addition of each study. Each point estimate is the cumulative hazard ratio in a way that the first study (LIFE 1997) showed only point estimate of LIFE 1997. The subsequent point estimate is the pooled estimate of LIFE 1997 and AFFIRM 2001, the third estimate is the pooled estimate of LIFE 1997, AFFIRM 2001 and SPORTIF III and IV 2002, and so on. Therefore, a decrement in the pooled estimate demonstrates a temporal decline in hazard ratio in published studies.

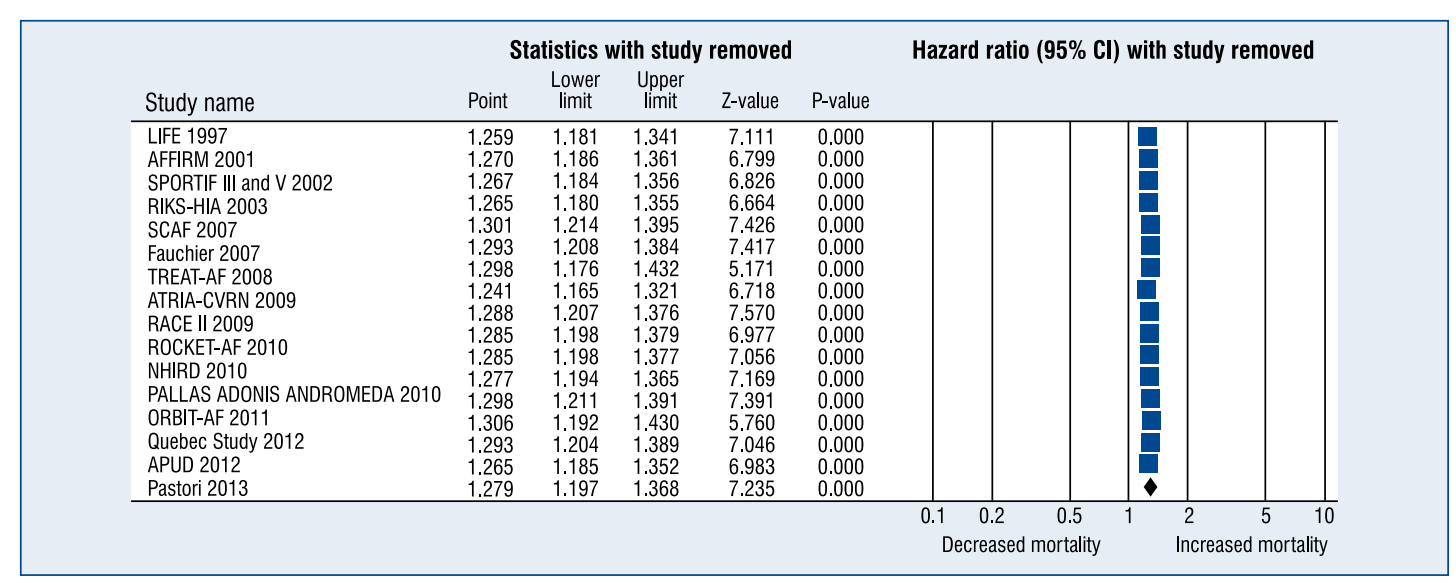

Supplementary Figure 5. One-study removal plot showing consistent estimates with removal of each study with each estimate. The corresponding hazard ratio in front of each study is the pooled hazard ratio after removal of that particular study. For example, the hazard ratio in front of LIFE 1997 is the pooled hazard ratio of all the other studies without including LIFE 1997. Such a plot demonstrates if one of the study has significant influential effect on the pooled estimates of meta-analysis. In a possible scenario, if a particular influential study is removed, the corresponding pooled hazard ratio may become insignificant. Here all of the corresponding pooled hazard ratios are significant, suggesting that none of the studies had particular influential effect on the pooled estimate.

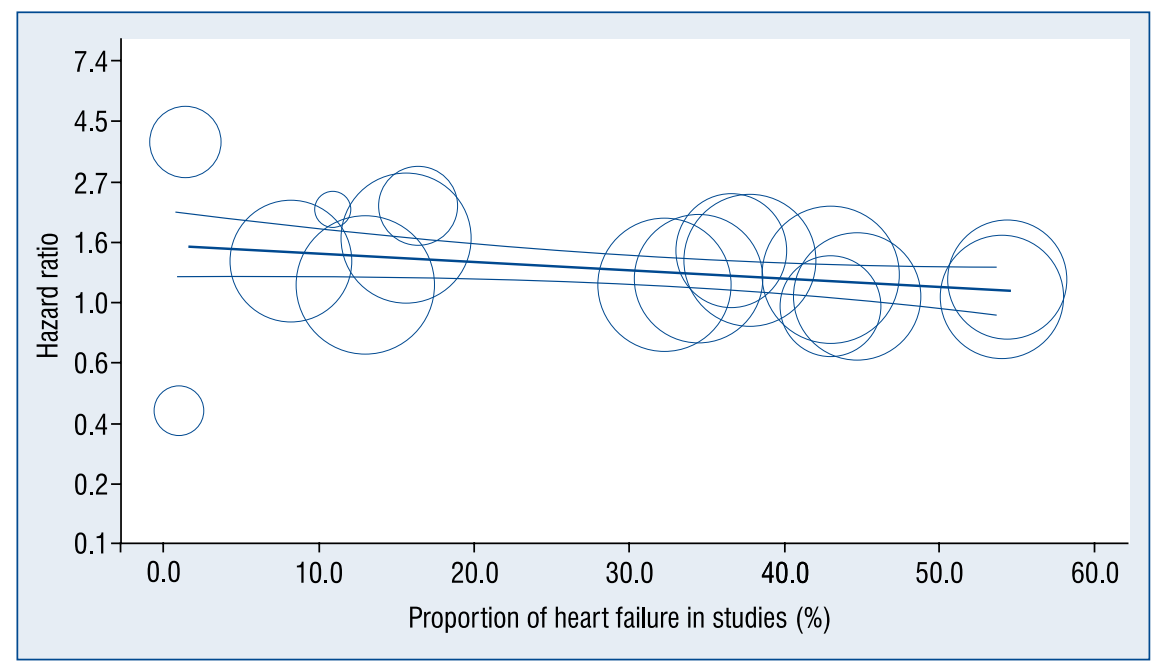

Supplementary Figure 6. Meta-regression plot showing a downsloping regression curve of hazard ratio across studies with increasing prevalence of heart failure patients for association of digoxin with mortality. 